Comparative Philosophy Volume 7, No. 2 (2016): 1-25

Open Access / ISSN 2151-6014

www.comparativephilosophy.org

\title{
FROM POLITICAL LIBERALISM TO PARA-LIBERALISM: EPISTEMOLOGICAL PLURALISM, COGNITIVE LIBERALISM \& AUTHENTIC CHOICE
}

\author{
MUSA AL-GHARBI
}

\begin{abstract}
Advocates of political liberalism hold it as a superior alternative to perfectionism on the grounds that it avoids superfluous and/or controversial claims in favor of a maximally-inclusive approach undergirded by a "free-standing" justification for the ideology. These assertions prove difficult to defend: political interpretations of liberalism tend to be implicitly ethnocentric; they often rely upon a number of controversial, and even empirically falsified, assumptions about rationality--and in many ways prove more parochial than their perfectionist cousins. It is possible to reform political liberalism to address these challenges, but generally at the expense of the supposed normative force and universality of the liberal project. However, this para-liberal approach is much better in keeping with contemporary findings in sociology, psychology and cognitive science--and can much more effectively accommodate the illiberal challenge.
\end{abstract}

Keywords: pluralism, liberalism, rationality

In "Perfectionist Liberalism and Political Liberalism," Martha Nussbaum (2011) persuasively argues that political liberalism is superior to its perfectionist cousin. However, her critique of perfectionism also problematizes Rawls' account of political liberalism-particularly as it relates to his account of "reasonableness" vis a vis comprehensive doctrines (CDs) and life plans (LPs). In response, Nussbaum attempts to refine Rawls' account to make it more inclusive-however, her alternative conception of political liberalism may actually be more parochial than that of Rawls, and seems to rest uneasily atop a series of profound contradictions. Yet, if we render her position more consistent, while the inclusivity problem is largely addressed, the normative force of political liberalism seems to be severely undermined-especially in contexts which are not already predisposed towards liberal ideologies, systems and institutions.

This dilemma arises out of the brute reality that, in many instances, there is not a clean correspondence between promoting the will (or even the interests) of a

AL-GHARBI, MUSA: Paul F. Lazarsfeld Fellow in Sociology, Columbia University, USA. Email: musaalgharbi@gmail.com 
given population and advancing liberal practices and institutions therein. In the event of such a conflict, the internal logic of political liberalism seems to not only allow, but to mandate, deference to the former-even if the resultant society exceeds the bounds of liberalism, per se.

\section{WHAT IS THE PROPER BASIS OF LIBERALISM?}

Nussbaum begins by drawing a distinction between political and perfectionist strains of liberalism. As she sees it, the primary difference between these interpretations is how the central principle(s) are derived and justified: be they pluralists or monists, perfectionists have a definitive vision of the Good which individuals and governments must universally strive to promote and/or maximize. In virtue of this, she argues, perfectionism tends to be predicated on bold metaphysical premises on which political liberals can, and often try to, take (ostensibly) agnostic positions.

Nussbaum identifies Raz as a perfectionist par excellance: throughout his work, he identifies autonomy as his central value ${ }^{1}$--insisting the role of the state is to create space for agents to exercise and refine their free agency. Raz is also a pluralist, declaring the doctrine to be independently true but contingently significant: pluralism has value in virtue of autonomy. Nussbaum's interpretation of Raz is as follows: the ultimate value of autonomy when paired with the objective truth of pluralism leads (inevitably) to liberalism as the optimal means of mitigating incompatible, yet rational, comprehensive doctrines and life plans.

Nussbaum sees two major problems here: Raz's assertion of autonomy as the ultimate value and his claims about the objective truth of pluralism. ${ }^{2}$ Both of these claims seem highly controversial. In fact, as is apparent from their own countermodels, many of Raz's fellow perfectionists would reject autonomy as the ultimate value, or reject his claims about pluralism's independent truth (or else, its contingent/subordinate value). Bentham, for instance, famously decried the notion of natural rights as "nonsense upon stilts," holding that liberty, autonomy, etc. are instrumentally rather than intrinsically valuable (insofar as they prove useful in maximizing the good). He was also a monist about the good: pleasure (or the

\footnotetext{
${ }^{1}$ Raz may not be as committed to autonomy as Nussbaum seems to believe. He consistently states that much like pluralism, the value of autonomy is contingent--free agency only has value if spent in "worthy" pursuits (Raz 1987). And it is rationality which divides the worthy pursuits from the unworthy: it is acceptable to violate agent's autonomy if they are acting irrationally; the purpose of the state is to promote rational choices and actively suppress irrational ones; the purpose of ethics is to rationalize behavior (Raz 2000). This implies that rationality is actually Raz's ultimate value. The significance of autonomy is subordinate to rationality in much the same way as pluralism to autonomy.

We should also note that, while not as rigid, there is a similar current in Rawls' thought: he insists that ethics is about maximizing certain types of positive outcomes - and on the individual or social level, one will be more likely to realize these through acting rationally (Rawls 1971, sections 63-64). Accordingly, regardless of whether we are discussing the philosophies of Rawls or Raz, the rational course of action will typically be the same as the ethical course of action, at both the personal and societal levels.

${ }^{2}$ Throughout, pluralism will refer to the belief that there are multiple (irreducible and often conflicting) moral "goods."
} 
avoidance of its inverse, pain) is the marker by which we deem an act to be right or wrong. So, Bentham, while a perfectionist, would reject both of Raz's central theses. And beyond the sphere of perfectionist liberalism, or liberalism in general, the supposed universality of these premises seems even more suspect.

Nussbaum believes that doctrines such as these cannot plausibly serve as the foundation for liberalism because many, perhaps most, would outright reject them; moreover, they may simply be false: if one must embrace Raz's stratified pluralism as an axiom in order to justify liberalism, it is going to be virtually impossible to establish or promote liberal systems and institutions (especially outside of Western contexts, but even therein). This dilemma is particularly salient when it comes to justifying state coercion or demands for sacrifice: if difficult/controversial policies or states of affairs can only be substantiated by means of an even more problematic explanation, the most intelligent response for those most affected would likely be to reject or resist whatever is being imposed upon them.

This problem is not unique to Raz-virtually any perfectionist account of liberalism will run up against this barrier. Nussbaum views this as the central defect in perfectionism: these visions can only be really justified if and when agents share the (typically idiosyncratic) convictions of various perfectionist thinkers. If one or more fundamental (often highly objectionable) premises fails, the entire system moreor-less collapses in upon itself.

Of course, a perfectionist may claim that their systems are not rendered false simply because they cannot gain traction with those who reject critical axioms. After all, if they have successfully seized upon an objective truth, it would remain true even if no one believed it. However, the sheer level of disagreement in the literature suggests that most perfectionists have not stumbled upon universal truths - most, if not all, of them must be wrong in various ways and to varying degrees; in fact, most of them must be guilty of radical errors.

In any case, Nussbaum's argument is more pragmatic than metaphysical: Even in the (inconceivable) event that some perfectionist succeeded in defining a system which would be objectively optimal in all contexts - it will have a difficult time ever getting adopted, successfully implemented, or remaining viable unless enough of the public can be brought on board - that is, absent a level of coercion which the relevant ideology may, itself, prohibit (or "on the ground" realities may prevent). However, this consensus seems unlikely if the justification for these systems and institutions hinges on idiosyncratic and highly-objectionable premises, regardless of their truthvalues (if determinable at all). Accordingly, if it is to have any hope at universality in practice, liberalism needs to be grounded in some other way.

Enter Rawls. In his Political Liberalism he proposes a "free standing" justification based on minimal overlapping consensus. ${ }^{3}$ Nussbaum believes that an advantage of

\footnotetext{
${ }^{3}$ Larmore, to whom Nussbaum traces the origin of political liberalism, described it as "a core morality that reasonable people can accept despite their natural tendency to disagree about comprehensive visions of the nature of value and so in particular about the merits of pluralism and monism." In short, political liberalism is intended to have its own moral content, but one which is "sufficiently
} 
this consensus-building approach is that citizens will have a greater stake in the principles thereby derived due to the role they, themselves, played in establishing them (ditto with regards to the resultant social systems and institutions). These attachments, which would arise organically in political approaches to liberalism, would be largely absent in "top-down" perfectionist approaches. Accordingly, Nussbaum suspects that systems and institutions derived from political liberalism will be more widely-adopted and stable over time.

However, while she believes the political approach is the right way to respond to the shortcomings of perfectionism, Nussbaum argues that controversial (and superfluous) claims sneak into Rawls' conception and may undermine his project on several levels.

\section{DEFINING THE DEBATE}

As Nussbaum sees it, what is at stake in the discussion between herself and Rawls is how to evaluate comprehensive doctrines and life plans-more specifically, how to mitigate "reasonable disagreement" in pluralistic societies. This question has two major components:

1. How should a society define which comprehensive doctrines (CDs) and life plans (LPs) are reasonable or unreasonable in order to enjoin the former and resist the latter?

and

2. How should the state navigate "reasonable" disagreements between its citizens, or between citizens and the state, given finite resources and conflicting agendas?

Nussbaum's analysis is primarily dedicated to the former, more foundational, question - albeit with implications for the latter, both obvious and subtle.

A further critical distinction concerns who is evaluating these CDs and LPs: is it a question of how individuals within a society should evaluate/define their own CDs/LPs? Or how the state should define, restrict, or encourage options for citizens? Here, Nussbaum is concerned with the latter, although there will be substantial overlap--especially insofar as the state's actions exert profound influence over individuals and their reasoning.

As she sees it, the most essential problem with Rawls' conception is that, at various points in Political Liberalism (and other works) he seems to conflate "reasonableness" and "rationality." Moreover, while he takes care to draw a distinction between rationality as a personal human capacity and "public rationality" which governs civil participation and institutions, Nussbaum demonstrates that this

abstemious, both in content and grounding, to avoid controversial ideas of the type that divide citizens who reasonably disagree." (Nussbaum 2011: 15-6) 
differentiation also frequently grows fuzzy-becoming especially problematic in those instances where the distinction between "reasonableness" and "rationality" is similarly unclear. There is a sense in which Nussbaum's task, therefore, is twofold:

1. To underscore that public rationality may legitimately include apparently "irrational" views because...

2. These positions may nonetheless be "reasonable."

Here, "reasonableness" refers to ethical legitimacy, contrasted to "rationality" which denotes soundness (logical, epistemological). While Nussbaum believes that "reasonableness" and "rationality" often (perhaps typically) travel together, there will also be many cases in which an action, belief, etc. may be "reasonable" but not "rational" (or vice-versa).

\section{POLITICAL LIBERALISM, REFINED}

In defining "reasonable" CDs and LPs, Rawls sets forward a number of criteria which appear to be more "theoretical" than ethical (that is, they seem to be concerned more with "rationality" than "reasonableness"), including:

1. One's CDs \& LPs should be more-or-less internally consistent

2. They should be ranked, or at least be capable of being decisively prioritized in the event they do conflict

3. They should be more-or-less stable over time, drawing from some established intellectual tradition - although they cannot be too rigid because...

4. They also must be derived from, or at least responsive to, evidence, reason, etc.

Nussbaum then demonstrates that "many" widely-endorsed CDs and LPs so not meet these criteria. This is a problem because Rawls, like Raz, believes that the state should work to create space for "reasonable" options to flourish while suppressing "unreasonable" ones. Accordingly, political liberalism, as formulated by Rawls, may exclude a number of CDs and LPs which are quite popular and more-or-less benign to the broader liberal project. While Rawls does build a number of caveats into his conception which would restrict the ways the state could go about marginalizing these options, Nussbaum argues that many would nonetheless feel unjustly persecuted and/or excluded - especially given that CDs and LPs tend to be profoundly reflective of people's sense of identity and search for meaning.

In driving this point home, she draws an analogy between an individual criticizing another person's dearly-held beliefs vs. the government doing it: In person-to-person interactions, challenging another's views can serve as a sign of respect. However, these sorts of confrontations are complex affairs - it requires a high amount of social nuance to know when, how, and how far to push back against someone's position in a constructive fashion. Many of the factors essential to carrying this out effectively will be context-dependent, often drawing from a previously-established intimacy between 
the parties. And of course, if the interlocutors are engaging in good faith, both parties

should enter the exchange willing to change their views in accordance with "the facts."

Interactions between a state and an individual are nothing like this: The state cannot exercise this sort of deftness tailored for each individual and each circumstance. The exchange is largely one-way - the individual does not have a comparable ability to influence the state as the state does over the individual.

This leads to Nussbaum's more general concern: a position held by the state is fundamentally different than a position held by any particular member of society (speaking for and as himself). A government expressing an opinion affects how one feels in their society, how one feels about said society, how one feels about themselves, or even how others in society feel about a given person or group - and in a much more drastic way than the expressed opinions of individuals. Moreover (perhaps more important), a government's ideological position informs state policy in a host of subtle and not-so-subtle ways, with the potential to profoundly (and adversely) impact someone's life on a scale that views of individuals typically do not.

In turn, this sort of exclusion and discrimination can result in a host of destabilizing second-order effects on political systems and institutions insofar as the disenfranchised reject and possibly seek to disrupt or dismantle the order achieved at their expense. In order to avoid these outcomes, and to better live up to the pluralistic ideals of political liberalism, the state should adopt a maximally-inclusive definition of "reasonableness." This entails restricting the definition of "reasonable" to ethical criteria rather than theoretical ones.

\section{THE ROAD NOT TRAVELLED}

While Nussbaum's argument is compelling, there is a much simpler and perhaps more effective means of making her case against Rawls; the criteria he sets out for "reasonableness" do not seem to bode well in the face of contemporary research in psychology and cognitive science:

1. People's doctrines and beliefs are not nearly as systematic as we like to think (VanGelder 1995); we do not have conscious access to a good deal of our mental contents (Bar-Anan et al. 2010; Clark 1994; Gendler 2008); our mental states are not nearly as malleable as many political philosophers suggest (Ariely 2010).

2. Desires and preferences are not prioritized/ prioritizable. While we can, upon demand, make a list of what we perceive as our aspirations or interests, and rank them in some order, these confabulations are not necessarily reports about our actual mental process/states, which are largely opaque to introspection. In fact, these accounts are easily falsifiable (Davidson 1982). In general, we are fairly bad at predicting what will make us happy/unhappy, how happy/unhappy various things will make us, and for how long--insofar as 
it is even sensible to reduce these mental states into quantitative measures (Gilbert \& Wilson 2000).

3. Our intuitions are wildly unstable - be it from person to person, or even for the same person across different times and circumstances (Alexander \& Weinberg 2007).

4. We do not know how or why we came to hold particular beliefs, desires, etc. (Weinberg et al. 2001; Haidt et al. 2000). Our justifications towards this end, even when sincere, are often simply wrong (Johnson 1997; Loftus 1996; Nisbett \& Wilson 1977).

5. Cognitive sophistication actually exacerbates rather than mediates many of these "problems" (Hertwig \& Todd 2003; Kornblith 1999; Mercier 2010; Uhlmann et al. 2009; West et al. 2012). For this reason, among others, attempts to "rationalize" people and institutions may do more harm than good (Morozov 2013; Popper 2013; Taleb 2012).

In short, neither Rawls, nor Nussbaum nor anyone else actually has CDs or LPs which correspond to Rawls' criteria, nor could they plausibly do so. People simply are not wired that way. ${ }^{4}$ One can articulate CDs and LPs superficially compliant with Rawls' criteria, but these abstracta will have precious little connection to one's

4 In light of these facts, Rawls' notion of personal "rationality" fares little better than his account of "reasonableness." For instance, in A Theory of Justice Rawls sets out the following characteristics of a rational agent (Rawls 1971, sections 15, 25-7 \& chapter 7):

1. People (generally) strive to maximize their share of primary goods (defined broadly as rights $\&$ liberties, opportunities \& powers, income \& wealth, and a sense of self-worth).

2. Accordingly, people generally (implicitly or explicitly) make decisions by weighing costs $\mathrm{v}$. benefits, risks v. payoffs, etc. wherein what is at stake is one's share of primary goods.

3. People are able to accurately identify and rank their desires, needs and preferences (and to accurately anticipate what these will be in the future) - they use this information to determine how to utilize their share of primary goods in the service of their system of ends.

4. (Typically) Through deliberation, people form rational plans to achieve these ends, taking into mind (among other considerations such as timing and scheduling) the likelihood their plan will succeed relative to its costs and benefits as compared to alternatives.

He further asserts that people can control or change their beliefs, preferences etc. (Rawls 2001: 254):

"We are assuming that people are able to control and revise their wants and desires in light of circumstances and that they have responsibility for doing so, provided that the principles of justice are fulfilled, as they are in a well-ordered society. Persons do not take their wants and desires as determined by happenings beyond their control. We are not, so to speak, assailed by them, as we are perhaps by disease and illness so that wants and desires fail to support claims to the means of satisfaction in the way that disease and illness support claims to medicine and treatment."

Notice that there is substantial overlap, both implicit and explicit, between this picture of personal rationality and Rawls' description of public rationality offered up by Nussbaum. However, neither conception seems to comport well with the scientific consensus on how people think and make decisions. 
actual states of mind, will have a negligible impact upon one's actual behaviors, and if realized, would have an unpredictable (often detrimental) effect on one's actual happiness.

However, CDs and LPs are held to be significant strictly to the extent they alternatively reflect and inform one's mental states. Absent this connection to how people actually think, feel, and behave CDs and LPs would be irrelevant with regards to political philosophy; it wouldn't really matter, for instance, if a government suppressed them. Similarly, it would be trivial if agents generated explicit CDs and LPs which are superficially compliant with Rawls" "reasonableness" criteria if these commitments failed to meaningfully guide people's thoughts and actions. This is a fatal defect: insofar as CDs and LPs must veridically (rather than merely ostensibly) correspond to these theoretical criteria in order to be reasonable, no CDs or LPs are, in fact, reasonable - not for anyone, now or in any foreseeable future.

This reductio proof would altogether remove the normative force from Rawls' theoretical criteria, even from a practical standpoint (let alone their supposed ethical force, ${ }^{5}$ which is reliant heavily upon Rawls' notion of "goodness as rationality") thereby forcing political liberals towards Nussbaum's conviction that the criteria for "reasonableness," must be non-theoretical.

Such an argument is particularly elegant because Nussbaum and her interlocutors are united in their agreement that social systems (and even individual CDs and LPs, albeit to a lesser extent) must be compliant with non-controversial science and/or responsive to empirical evidence. The handful of facts relied upon to make this case against Rawls are, in turn, well-established within the sciences (Lakoff \& Johnson 1999). This leaves her interlocutors in a Catch-22:

The findings of contemporary cognitive science and psychology mandate that they abandon their views about rationality. If they choose to cling to their position in defiance of the scientific consensus, rationalism is thereby rendered hollow and inconsistent insofar as it requires adherents to modify their positions in accordance with the scientific consensus, well-formed argument, and empirical evidence. So either way, their position fails absent radical modification. ${ }^{6}$

\footnotetext{
${ }^{5}$ Rawls has a lot riding on his depiction of human rationality: his two principles of justice were derived explicitly by resting upon this conception. He asserts that it is the responsibility of individuals to formulate Rational Life Plans in order to best utilize their share of social goods in the service of their system of ends, going so far as to equate rationality with goodness itself (another possible parallel to Raz).

Moreover, the "fact" that people are essentially (if imperfectly) rational is supposed to make his theory appealing and effective in "real-world" contexts. Rationality is supposed to ensure that a "wellordered" society is viable, stable, and prosperous - again, even his accounts of "reasonableness" and "public rationality" are difficult to distinguish from his description of personal rationality. Accordingly, if it turns out that this conception is deeply misguided, the normative force of his Theory of Justice evaporates, both at the individual and societal levels.

${ }^{6}$ The reductio proof, in addition to making an elegant case against Rawls' theoretical criteria, could also undermine Raz's perfectionism. Insofar as his view is correctly described as having rationality for its highest value (followed by autonomy, whose value is contingent upon rational exercise, and pluralism, whose value is contingent upon free agency) - if it turns out that people simply are not rational, Raz's ideology becomes akin to a rudderless ship.
} 
While these considerations are important insofar as they allow us to more simply and profoundly critique Rawls' superfluous criteria regarding "reasonable" CDs and LPs, this empirically-driven and scientifically-based approach will also elucidate the problems with Nussbaum's counter-model...

\section{PEOPLE OVER DOCTRINES}

Rawls' problematic "reasonableness" criteria were derived from his broader corpus of work. However, his original position (no pun intended) was that a person could be ethically reasonable by meeting two core conditions: first, they must be willing to propose fair terms of cooperation and abide by them, provided others do as well (let us call this the "good faith" condition). Second, they must accept the "burdens of judgment," which is to say they must acknowledge that many of the disagreements between interlocutors are not easily attributable to either party being factually wrong, illogical, deviant, etc. In many cases the truth will be more-or-less indeterminable - in fact, the virtual entirety of human judgment occurs under uncertainty of varying degrees.

Again, foundational to the free-standing justification of liberalism is what Nussbaum calls the "method of avoidance:" while a position cannot be entirely neutral (almost by definition), one should generally refuse to rely upon controversial metaphysical, religious, epistemological, or even ethical doctrines (Nussbaum 2011: 16). On these grounds she accepts Rawls' "good faith" condition; however, she suggests his "burdens of judgment" criterion may be superfluous and theoretical in nature, and so she sets it aside along with the other aforementioned theoretical criteria.

In its stead, she offers that a view can be described as "ethically reasonable" insofar as it is grounded in the notion of equal respect for persons. Consequently, individuals should tolerate - and institutions should be as equivocal as possible between-conflicting CDs and LPs, even if they seem illogical, provided they are ethical.

That is, liberalism should be premised on a respect for persons rather than their views. Nussbaum analogizes this respect to the Kantian notion of viewing people as

Of course, Raz, Rawls and most other rationalists are perfectly willing to consider that people are imperfectly rational - constrained by cognitive limitations, biases, misinformation/disinformation, ignorance, and other extenuating circumstances (a list of exceptions whose indefinite length should be troubling in itself). However, these concessions still seem inadequate: the entire Enlightenmentderived discourse about human rationality is likely ill-formed (al-Gharbi 2014).

In fact, even if Raz relies on a fairly idiosyncratic, complex or arcane (or perhaps vague) notion of "rationality" which eludes straightforward definition, it is a relatively safe assumption based on a sampling his writing that, commensurate with most analytic political philosophy, his vision of human cognition is sufficiently out of step with the scientific and sociological consensus to render his account deeply problematic and (at best) in need of substantial reform. 
ends, and never as mere means: ${ }^{7}$ we respect others' convictions because we understand them to be worthy of the same dignity as our own.

\section{SHE WHO LIVES BY THE SWORD...}

While Nussbaum makes a compelling argument for rejecting Rawls' burdens of judgement criteria, her replacement (equal respect) may itself be a spurious violation of the method of avoidance-particularly insofar as she conflates equality with "identity," "equivocality" etc. This is not the only conceivable method of fairness. To help motivate this concern, consider the value of respecting women:

According to most liberal interpretations (including Nussbaum's own), the best way to show respect for women is to treat them exactly the same as men. However, the classical conception of justice is not "to treat everyone the same" but instead "to treat those who are the same in a roughly commensurate fashion"-according to which there are two forms of injustice (Nietzsche 2011: 45-50):

1. Treating people significantly different when they are in fact the same, or...

2. Treating people the same when they are importantly different.

In this spirit, traditionalists argue that the liberal conception fails to respect women qua women: they are only valued in those aspects in which they can easily be interchanged with men (i.e. as a worker, a voter, a consumer, etc.). It is rarely considered just how much is built into this discourse. For instance, it is presupposed that the only (or in any case, best) ways of empowering women, and people in general, is to give them opportunities for prolific professional titles, higher salaries, etc. (Penny 2011). That there are alternative, perhaps more contextually relevant, forms of power, significance, or satisfaction is overlooked in favor of capitalist interpretations of value. ${ }^{8}$

7 Gaus (2009) convincingly argues that the Kantian notion of autonomy also underlies virtually all liberal approaches, be they political or perfectionist, despite pretenses such as the "Method of Avoidance." Of course, for our purposes Kant's conception of autonomy is no less problematic than his formulation of respect-and mutatis mutandis, the arguments presented here against presuming the universal legitimacy of Kantian "respect" would apply just as well to "autonomy."

${ }^{8}$ The primary way liberals attempt to enhance well-being is to promote so-called "primary goods," and to empower beneficiaries to use them however they please (within reason). However, the value of these goods is highly relative, as are socio-cultural interpretations of what goods such as "autonomy" mean - and in many cases these resources have diminishing returns or their abundance can even become odious or foster greater social strife (Easterlin 2005; Graham \& Pettinato 2001; Kahneman \& Deaton 2010; Markus \& Schwartz 2010; Sahlins 1974).

For instance, with regards to freedom and responsibility, the prevailing desire seems to have them in an authentic but definitively-bounded sense--with frontiers determined by indigenous values, norms, and frames of reference. Similarly, with regards to other primary goods, most people are satisfied when they have enough to live comfortably (beyond sustenance, typically at or just above what they perceive to be the "norm"). Accordingly, a ham-fisted proliferation or even imposition of various "primary goods" as defined in Western quarters (under the falsified assumption that people are "maximizers") is unlikely to improve people's lives as much as intended, and may even make them worse (Easterly 
In defiance of this paradigm, a traditionalist would argue that the best way to respect women is to acknowledge differences between the sexes and to honor gender roles. This neither entails nor implies treating women as 2 nd class citizens-instead, that women and men have reciprocal, complimentary, and interdependent (rather than identical) rights and duties. It does not disregard "women's rights" (e.g. sociopolitical participation, education, protection from violence/ exploitation), but rather radically changes the nature of feminism (Ahmed 2012; Lais 2013; Shams 2012). In fact, a more careful examination of social dynamics in "traditional" societies would reveal that women have a good deal more power than Western liberals generally assume.

The lives of women are often held to be more valuable than their male counterparts: men are considered to be expendable/replaceable (which is why they are subject to extreme physical labor, sent out to hunt or off to war, etc.). In the "high culture" of these societies, even a superficial survey of art--be it literature, music, or visual media--tends not merely to objectify, but to idolize women. This same reverence underlies calls to "defend women's honor," and motivated most of the great feats of mythical heroes (as well as the everyday efforts of ordinary men to provide for their families). Even calls for modesty of dress and segregation of the sexes are generally based in a concern about the weakness of men, and a fear of women's power over them, which they are held to often exert effortlessly and unintentionally.

While there may be much to critique about "traditional" views of women, it would be simply incorrect and ignorant to claim they were (are) generally viewed as weak or inferior to men. Instead, each sex was (is) held to exert different types of strength, cunning and other virtues, which are to be respected (utilized, protected against, lauded, feared) in their own ways. ${ }^{9}$ This remains the predominant view in most societies worldwide. Accordingly, insofar as Nussbaum identifies "equality" with something closer to "identity," her criteria seems to be grounded in problematic or controversial conceptual frameworks which much of the (illiberal) world would outright reject.

In fact, while Nussbaum frequently rails against the "new religious intolerance," regarding for instance, the hijab bans in France (Nussbaum 2013), she nonetheless blatantly rejects traditional gender roles, and would support the coercive enforcement, if needed, of Western-liberal parity between the sexes (Nussbaum 2000)--regardless of whether or not most of the women in a given context supported such a measure, or found the ideologies (and especially their external imposition) to be profoundly disrespectful to their people and their sex (Abu-Ludhod 2013), or even if many of those affected would subjectively evaluate themselves to be worse off (more

2014) — even setting aside the severe problem of perverse incentives/ ulterior motives on the part of those carrying out these paternalistic missions.

9 One of the primary differences between "modern" and "traditional" societies is the relative significance of the individual v. the community. The "traditional" demand that all citizens subordinate or even sacrifice their personal aspirations and well-being for the sake of fulfilling their culturally prescribed roles - this runs sharply against liberal sensibilities and likely contributes to misperceptions about gender relations. 
vulnerable, less valued as women or even human beings, etc.) after such a transition, which is often the case historically through the present (Kucera 2013).

As a second example, Prioritarian Perfectionists such as Nagel (1991) and Hurka (1996) hold that it is more important to develop the more capable, and to support and endorse "higher" achievements, in order to maximize the development of society (or even humanity) as a whole, even if such policies aggravate rather than moderate inequalities. Unlike Plato or Nietzsche, ${ }^{10}$ neither Hurka nor Nagel would hold that the more capable are morally or otherwise metaphysically superior to the less capable (and the determination of what achievements are "higher" or "lower" would be almost entirely technocratic on their account) - nonetheless their socio-legal prioritization of the aristos, their CDs, and their LPs would likely violate Nussbaum's view of equal respect - in practice, if not in theory.

Finally, in formulating his Entitlement Theory, Nozick (2013) demonstrates how morally justified inequalities can arise - not only in relation to wealth, but even regarding socio-legal rights, privileges, and duties. Disparities arise organically as a result of the labor and resource investments of various agents (or lack thereof), developed skills, abilities and expertise, as well as subsequent good-faith contracts, coalitions and associations with others, etc. (both historical and contemporary). While Nozick's account would not sanction privilege or discrimination based solely on race, gender, religion, etc., it does hold that that as an accident of history any particular arbitrarily selected (ethnic, sexual, religious, etc.) group may fare substantially better or worse relative to the average, or to any other group - and this need not denote any sort of wrongdoing which needs to be redressed. According to Entitlement Theory, even profound inequalities are not necessarily incompatible with fairness, and may not be indicative of disrespect - in fact, they may represent the fulfillment of these ideals. And so, while Nozick endorses Kantian equality, his interpretation of what this entails may prove "ethically unreasonable" on Nussbaum's account.

Yet it seems strange that apparently benign Western, secular, analytic-politicalphilosophical positions like Entitlement Theory or Prioritarian Perfectionism could be construed as "ethically unreasonable" and be therefore disqualified from the public sphere. These are certainly not the sort of views Nussbaum seemed to have in mind with her proviso. But even some of the views she was actively trying to restrict, such as illiberal religious or otherwise traditional systems of social arrangement, do not seem quite so unreasonable upon a more careful examination. In many cases, calling

\footnotetext{
${ }^{10}$ It is likely that an aristocrat a la Nietzsche or Plato would reply to Nussbaum's charge of unreasonableness as follows: the Kantian notion is actually tantamount to universal disrespect. It condescends to the "lower" classes by paternalistically coddling them, feeding delusions of grandeur rather than encouraging people to accept their station and the realities entailed thereby. And it disrespects the strong, of course, by castrating them on myriad levels. The result, they would argue, is that everyone is worse off. The best way to respect all parties would be to acknowledge the fundamental truth that all men were not created equal, and to arrange society accordingly. In short, this is another case where, despite a mutual commitment to respect, the positions of Nussbaum and her interlocutors would be diametrically opposed: "respect for all people" need not be cashed out in terms of Kant's "equal respect."
} 
these societies "hierarchical" may even be somewhat misleading and/or reductive-it may be more accurate to say they utilize notions of equality, respect, justice, etc. which are incompatible with those Nussbaum is relying upon.

In this light, the Kantian notions of "equality" and "respect" (and especially their conjunction, "equal respect") seem like extremely controversial premises to serve as the foundation for political liberalism. Ultimately, Nussbaum's vision may be more parochial than that of Rawls: beyond excluding many traditional social arrangements preferred by overwhelming majorities across much of the world, even the apparently innocuous views of her liberal colleagues could be construed as ethically unreasonable. Accordingly, Nussbaum's model fails to meet its own criteria of success: achieving greater inclusivity via a more finessed application of the method of avoidance. That said, it may be possible to salvage her project of reforming Rawlsian political liberalism by turning to, of all people, Rawls.

\section{RAWLS REDEEMED?}

In The Law of Peoples Rawls suggests that a society need not be liberal to be justeven going so far as to acknowledge that liberalism may be ill-suited to some particular contexts and circumstances. Accordingly, for the sake of minimizing war and other instability/suffering, and for promoting self-determination and the exercise of public reason-Rawls holds that illiberal societies should be tolerated by the international community, provided they are "decent" (Rawls 2010); a society can meet this threshold insofar as it is "well-ordered" to promote the public good, as understood within its specific socio-cultural context.

Nussbaum offers no such concession. In fact, like Raz, she supports suppressing or destroying templates which are incompatible with her "capabilities approach" to social justice, going so far as to endorse the dismantling of entire civilizations if needed on the grounds that "cultures are not like museum pieces which must be preserved at all costs" (Nussbaum 2000: 37). Of course, it is perplexing that in the same breath Nussbaum acknowledges the responsibility to protect and preserve cultural artifacts (which are what we generally store in museums), she also argues that the international community may have an obligation to mutilate many of the very cultures from whence such articles are derived. But let us sidestep her ill-formed analogy to address a more substantive incoherence:

In justifying these moral interventions, Nussbaum argues that the tolerance encouraged by Rawls and others is essentially condescending, and therefore, disrespectful. However, Rawls is very upfront about this himself. He implies that toleration is necessary due to the "regressive" nature of some cultures: they are in a sense, defective or deficient-it is not that they merely seem that way from the perspective of Westerners. But there may be situations in which the "cure" is, for various reasons, worse than the "disease." In short, Rawls would likely respond to Nussbaum's charge of condescension by simply acknowledging it as true, but offering that the primary alternatives seem worse (including her own). 
The irony is that Nussbaum's "solution" is no-less condescending: it is entirely patronizing to crusade on the grounds of "liberating" people from their "backwardness." In order to even hold this view, the patrum must feel a certain superiority over those they wish to guide (Easterly 2006). Accordingly, it seems strange to instantiate liberalism through paternalistic intervention, especially if coercive, given that "equal respect" is supposed to serve as the very foundation of the ideology on Nussbaum's account. Again, she herself acknowledges the condescension implied by paternalism in her arguments against perfectionists; concerns for this sort of disrespect and its second-order effects informed her calls for governments to be equivocal between CDs and LPs, even for positions which seem (theoretically) unreasonable. ${ }^{11}$

Nussbaum's entire argument for political liberalism hinges on respecting people over their doctrines - and, in turn, respecting aforementioned doctrines on the basis of respect for peoples. And yet, by Nussbaum's interpretation of political liberalism, large classes of people, much of the world (perhaps the majority of human beings) would be marginalized from political discourse and/or full participation in virtue of their doctrines insofar as they reject liberal values or institutions. More than that, these populations may actually have liberal systems/institutions forced upon them against their will, and likely against their interests. This is because, like Raz, Nussbaum's commitment to pluralism is contingent: acceptable only within the parameters of her capabilities approach.

While Nussbaum insists that societies can and should tolerate illiberal views, this applies only insofar as the beliefs in question are personal and not political. But presupposing this line can be drawn is itself question-begging. For instance, if one believed, as perhaps most of the world's population does in fact believe, that ethics (and accordingly, politics) cannot and should not be authentically separated from theology - there is no way to hold such a belief in a non-political way (it rejects the very distinction, which is secular). It is disingenuous to "allow" adherents to do something which is, in fact, impossible (such as holding a political view apolitically).

\footnotetext{
11 Nussbaum focuses nearly-exclusively on religiously-derived CD's and LP's to illustrate that a view may be "epistemologically" unreasonable while remaining "ethically" reasonable. In making this case, she claims that prolific authority figures of most of the world's major religions have accepted or even endorsed key ethical tenants of liberalism, especially regarding human rights and equality issues. And so despite the fact that adherents may endorse liberal positions due to their belief in the divine (as opposed to being convinced through logical argument), it seems crazy to marginalize those who could be easily co-opted instead.

But again, Nussbaum's "tolerance" extends only insofar as religious adherents do, in fact, recognize essential tenants of liberalism (in practice). Only those strains of the relevant religions/ worldviews which accept, at least politically, the ideal of "equal respect" will be permitted. This is significant, because those token liberal religious figures she cites (in the abstract) tend to be fairly unrepresentative of the faith traditions in question, and this is unlikely to change anytime in the foreseeable future (Kazmi 2014). Accordingly, her tolerance may not, in practice, extend as far as she seems to believe it would.
} 
Similarly with views about relations between the sexes, proper sovereignty/ legitimacy, etc.- - these are social (rather than "personal") positions. And in virtue of being sincerely-held beliefs, they should guide one's actions and interactions "in the world;" this may be all beliefs are in the first place. For instance, Wittgenstein (2009) argued that beliefs are not something "in the head"--they merely denote dispositions to act a particular way in certain contexts. One's beliefs are defined by how one acts in the world (Hadot 1995), not by means of words (or therefore, conscious thoughts).

In short, Nussbaum's claim that someone can hold social and ethical views in a strictly personal and non-political way seems dubious and fails to acknowledge or respect the scope and demands of the ideologies in question: if one is forbidden from promoting, working to instantiate, or otherwise meaningfully acting on these convictions - one is not really free to hold said belief(s) at all.

In fact, Nussbaum proposes that constitutions should be drawn up in order to render illiberal policies impossible (again, with the international community resorting to coercion, as needed, to establish and enforce these norms). Regardless of whether a plurality, a majority, or even the totality of a given public or their representatives supports policies or institutions which run contrary to Nussbaum's "capabilities approach," she believes they should be prevented from enacting them.

And so even if illiberals were permitted to promote their views in the "background culture," her exclusionary proviso would hollow out the whole principle of "free expression" - the point of which is not just to scream into a vacuum, but to influence the trajectory of one's society, impacting policy in a meaningful way. In societies where most, if not all, of the public subscribes to views which run contrary to Nussbaum's interpretation of Kant, the entire democratic process would become farcical insofar as her proviso was enacted: people would have the option of choosing between several options they find to be morally inadequate or outright immoral, and would be forbidden from enacting policies based on their values. It would be a misnomer to call such a situation a "free choice."

In fact, Nussbaum and her interlocutors (Raz, Rawls) are in agreement on this point, insisting that a public has to be given an adequate range of options in order for choice to be meaningful--and that a range of options cannot be considered adequate insofar as it presents people with paradigms they find to be worthless, repugnant or even harmful. And so, just as Nussbaum's greater "tolerance" proves to be almost purely semantic, her interpretation of pluralism lacks the robustness to realize her stated aspirations. However, mutatis mutandis, Rawls' position on illiberal societies may provide a way out:

\section{EPISTEMOLOGICAL PLURALISM}

Let us draw a distinction between "weak" epistemological pluralism and "strong" epistemological pluralism. Both Rawls and Raz endorse weak interpretations insofar as they acknowledge that different life experiences, opaque information environments, and various cognitive and perceptual limitations may lead people to different conclusions about many important issues - differences which cannot simply 
be attributed to one party or the other being ignorant, factually wrong or illogical (i.e. there are many "reasonable disagreements"). Similarly, they acknowledge that a great number of pursuits may have intrinsic worth, and that people vary in how they prioritize and utilize primary goods--and this is not only acceptable, it is laudable.

While these doctrines have a distinct metaphysical component (about the ultimate nature of value, etc.), they also entail many propositions about how people think, what they believe, and about which patterns of thought are good or bad. Nussbaum has argued that Raz and Rawls may have been too hasty in their (explicit and implicit) denigration of deferral to religious authorities, faith, or tradition. Similarly, she pointed out that many popular secular ideologies fail to conform to Rawls' theoretical criteria. We have sharpened these arguments by highlighting critical points of consensus from the scientific community about how people think. However, our investigation has subsequently suggested that Nussbaum may not have gone far enough - that perhaps her own view is actually narrower and more contentious than those she was criticizing, and many of her apparent concessions actually prove to be fairly shallow.

Despite discarding Rawls' theoretical standards as appropriate criteria for "reasonableness," and declaring the state's obligation to respect an individual's right to personal para-logical beliefs - Nussbaum nonetheless asserts that reason, argument and proof must hold a privileged position in the public sphere. She holds "practical reason" as a core capacity that "all democracies" should strive to promote. Much like her interlocutors, she seems to discuss terms like "reason," "logic," "argument," "proof," and "science" in a fairly homogenous and reductive fashion. Even in her defense of religion, she seems to acknowledge that most faith-based or otherwise traditional epistemologies are more-or-less illogical ${ }^{12}$ (although they should be tolerated as long as they get the "right" socio-political answer)-implying the existence of some unified and correct (perhaps objective?) "logic," external to religion and related ideologies.

Of course, given her broader project, it is convenient for Nussbaum to talk and think this way because it suggests the possibility of universal truths, or at the least, of reflective equilibrium even across radically different contexts - thereby enabling the establishment of universally recognized and enforceable norms (ideally, commensurate with her capabilities approach). Unfortunately, this sort of conception cannot long survive in the "real world."

Nussbaum partially acknowledges, albeit perhaps without fully understanding the profundity of, the fact that different cultures have different norms for structuring and evaluating arguments, different rules governing justifications, different standards of evidence, different notions of authority and priorities of authorities in the event they conflict, ad infinitum (Bichierri 2005; Foucault 2010; Nisbett 2003; Zerubavel 1999). She seems to overlook many other critical realities as well:

For instance, logic is not monolithic: within the "classical" domain (relative to Western norms and history), there are several modes of logic, with hosts of

${ }^{12}$ Contra, Henrich 2015: 97-116 
interpretations/applications of these systems, deployed in response to particular circumstances (Fetzer 1990). ${ }^{13}$ Beyond these options are "non-classical" logics, many of which are entirely secular but nonetheless subvert the rationalists' sacred principle of non-contradiction (Priest 2003, 2008). That is, even blatant contradictions do not necessarily indicate "illogic," especially given the ubiquity of phenomena which are not cleanly reducible to language (Polanyi 2009; Quine 2008).

Similarly, there is wide variance across or within contexts as to what counts as "science" (and in virtue of what), what are the best practices, how to mitigate conflicting evidence, etc. These definitions have and continue to evolve under contention, often in drastic ways (Feyerabend 2010; Foucault 1994; Kuhn 1996). Even the most rudimentary analysis of scientific practice reveals that whether (or where) research is published, or if a view receives traction, depends in large part (probably predominantly) on the person or institution from which it originates and/or the reputations of early endorsers and detractors. Ultimately, the paradigm which prevails is determined by a host of social, political, economic and personal interests (which often fueled the research in the first place). Science is not in the business of universal/objective/eternal truths, but of useful and provisional ones, as determined by a host of socio-cultural factors (Polanyi 1974). Speaking of "science" in universalist terms (or speaking of its findings as absolute truths) is indicative of failing to understand what it is, what it does, or how it works.

Moreover, underlying superficial semantic equivalences made by proponents of "universal values," there are often profoundly different notions of terms like "justice," "freedom" or "respect" across and even within socio-linguistic contexts (MacIntyre 1989), resulting in sometimes radically alternative conceptions of the systems, institutions, and practices best suited to fulfill, promote or defend these "shared" values (Taylor 2003) — and as we have previously explored regarding feminism, many of these interpretations will defy liberal sensibilities. In many cases, various facets of liberalism will even contradict one-another:

For instance, the classical conception of liberalism includes, among other things, a commitment to free markets, universal law, democracy, pluralism and secularismideologies which are not intrinsically compatible or necessarily intertwined (Schmitter 1994). In fact, these ideas were not historically compatible, even in

\footnotetext{
${ }^{13}$ Just as there are different modes of logic, each of which tends to work better or worse in particular circumstances, it may be helpful to think of alternative conceptions of justice (etc.) as different modes of these ideals. And as with logic, it may be that the more developed one's multi-modal ethical reasoning abilities are, the better-equipped one will be to handle novel, complex, or otherwise difficult situations.

Moreover, just as a recognition of different modes of logic does not prevent one from identifying logical fallacies (relative to that mode), or suggesting that another mode of reasoning may work better in particular instances--recognizing different ethical modes need not entail that all points of conflict are merely the product of cultural differences. However, divergence from one's own mode of reasoning could not, in itself, be held up as proof of an interlocutor's error. Instead, one would have to begin by engaging others on their own terms or via a collaborative "Third Space" (Bhabha 2004). The upside? This type of exchange, though more demanding, would likely prove far more productive as well (Haidt 2012; Kahan 2010).
} 
Europe. In many contexts, they diverge and conflict, and the balances struck in any particular context are not easily exported to others (Asad 2003; Gillespie 2009; Schmitter 1995). As a result of these contradictions internal to liberalism, attempts to instantiate or promote contemporary Western values and institutions in exogenous contexts is likely to foster instability and blowback rather than universal peace and prosperity. In many cases liberalism will prove inferior to alternative social arrangements (such as state capitalism, illiberal democracy, legal pluralism, etc.) at realizing the will and interests of a given population in their particular circumstances (Zakaria 2007, Miller 2015); individually or collectively, while they may often prove benign, the liberal doctrines are neither universal, necessary, nor inevitable.

In turn, cognitive and conceptual diversity is refracted and compounded in profound ways given the rich and complex interplay between genes and memes (Cosmides \& Tooby 1992; Sterelny 2003; Todd et al. 2010): differences in natural and social environments affect the development and trajectory of various cognitive abilities, which in turn affect how agents interact with and shape their environments (on and on). And so, it is not just about respecting differences in "software" (e.g. different languages framing reality, different cultures and history, etc.) but also "hardware" (Rushton \& Jensen 2005; Gallese \& Lakoff 2005; Lakoff \& Nunez 2001; Sterelny 2012; Halpern 2012). ${ }^{14}$

These realities are constitutive of "strong" epistemological pluralism, the internalization of which would resolve Nussbaum's objection about condescension: it would not be a matter of turning a blind eye to "injustice" in other contexts, but of understanding that there are different (often radically alternative) notions of justice, respect, etc. with no conceivable objective way to settle between them. As Nussbaum points out, authentic respect for differences renders tolerance superfluous - and with it, the accompanying condescension.

Unlike monism/pluralism about the Good, whose "proof" consists largely of arguments from various axioms (often pluralism or monism is simply taken as an axiom itself), strong epistemological pluralism must be acknowledged, first and foremost, because it is a brute fact about the world; it need not be accepted dogmatically, as it can be empirically established and observed. Accordingly, Nussbaum and her interlocutors are bound by their own ideologies to accept it insofar as they defer to established science, reliable evidence and well-formed argument.

There is another sense in which their own views mandate a recognition of strong epistemological pluralism: talk about freedom of conscience, aesthetic/moral

\footnotetext{
${ }^{14}$ Given the history of eugenics and related ideologies, it is important to underscore that between these cognitive and conceptual paradigms, there is no universal "better" or "worse." Evolution, be it social or biological, is about change, not progress. Whether or not any adaptation is good or bad is determined by fitness, in light of the particular environment an organism finds itself in. This is not to take a relativistic position, as certain options are better than others in particular contexts--although superior fitness would have to be established on a case-by-case basis, rather than being taken for granted a priori (moreover, performance differences can often be mitigated by changing the format/ presentation of the relevant data [Gigerenzer \& Hofferage 1995]). However, it is highly-improbable that any particular paradigm will be superior to all others, or even any particular counter-model, in every circumstance.
} 
pluralism etc. cannot be particularly deep or meaningful without it. This latter fact has been acknowledged by Nussbaum's friend and colleague Amartya Sen (2005), preventing him from even attempting to list and weigh universals such as Nussbaum's core capabilities. Instead, these determinations must be made in relation to, and with the participation of, the societies in question (Chambers 1999).

However, an acceptance of strong epistemological pluralism need not be a deathknell for political liberalism. One can even affirm Nussbaum's convictions regarding the appropriate centrality of reason in public discourse, etc.-albeit while acknowledging and respecting profound epistemological differences, as well as the second-order effects of these differences, vis a vis the formation or endorsement of social, political and economic systems, institutions, and practices (Kahan 2007).

While accepting strong epistemological pluralism, Nussbaum might be able to salvage her broader project by maintaining Rawls" "good faith" criteria for reasonable agents, and then adding that a CD or LP can be "reasonable" if rooted in respect for people, however understood and expressed within the specific relevant contextshedding the needlessly controversial caveat about equality, as well as the ethnocentrism and other problems related to Nussbaum's interpretation of Kantian respect.

\section{CONCLUSION:}

\section{FROM POLITICAL LIBERALISM TO PARA-LIBERALISM}

In "Perfectionist Liberalism and Political Liberalism" Nussbaum demonstrated that both perfectionist and political strains of liberalism are unduly parochial insofar as they rely on dubious and, ultimately, superfluous criteria of "reasonableness." By streamlining these criteria to focus exclusively on ethical (rather than theoretical) considerations, she hoped to enrich and expand the range of comprehensive doctrines and life plans which would fall within the parameters of political liberalism.

We have demonstrated that Nussbaum's reformulation fails to achieve its stated aim because it fails to adhere to its guiding principle: the "method of avoidance." In particular, Nussbaum seems to privilege as objectively-correct her culturallyinformed and somewhat idiosyncratic conceptions "respect," "justice" and "equality." As a corrective, political liberals can embrace strong epistemological pluralism, recognizing the reality and legitimacy of multiple conceptions of "respect" (and related core ethical principles).

However, given their other commitments, an embrace of strong epistemological pluralism may compel political liberals to accept a wide range of social arrangements derived from these alternative conceptions - many of which will not be liberal, but may nonetheless be demonstrably "reasonable" (Youngs 2015)-likely expanding the sphere of protected beliefs, practices and forms of social arrangement far beyond Nussbaum's original intention.

The good news for Nussbaum is that because contemporary Western notions of respect tend to be intimately tied to liberalism, within Western societies there would still be grounds for rejecting many of the views she would want to decry as 
"unreasonable." In fact, in non-Western contexts, many practices Western liberals may want to abolish could be defined as "unreasonable" even relative to indigenous conceptions. Consensus is possible on many issues - even to the point that some rival conceptions of core ethical notions may be more-or-less reconcilable through goodfaith cross-cultural negotiation and exchange. ${ }^{15}$

However, in the event of persistent differences, provided that a given practice, system or institution is "ethically reasonable" relative to the socio-cultural context in which it exists, liberals must not only tolerate but respect these disparities, however radical they may be. This embrace of comprehensive doctrines, life plans, and systems of social organization strictly on the basis of their (contextualized) ethical reasonableness-without regard for conformance to Western-liberal norms or expectations--can be described as para-liberalism.

\section{ACKNOWLEDGEMENTS}

The author would like to thank Dr. Steven Wall (University of Arizona, Department of Philosophy) for his generous guidance and support in formulating the initial draft. $\mathrm{He}$ is also indebted to the anonymous peer reviewers at Comparative Philosophy, whose insightful questions and constructive criticism were invaluable in refining this essay.

\section{REFERENCES}

Abu-Ludhod, Lila (2013), Do Muslim Women Need Saving? (Cambridge: Harvard University Press).

Ahmed, Leila (2012), A Quiet Revolution: The Veil's Resurgence, from the Middle East to America (New Haven: Yale University Press).

Alexander, Joshua \& Jonathan Weinberg (2007), "Analytic Epistemology and Experimental Philosophy", Philosophy Compass, 2 (1): 56- 80.

Ariely, Dan (2010), Predictably Irrational: The Hidden Forces that Shape Our Decisions (New York: Harper Perennial).

\footnotetext{
${ }^{15}$ However, it is also plausible that this unity will prove elusive. For instance, let us stipulate an objective reality in which we all are immersed. The preceding investigation strongly suggests that human beings are incapable of perceiving, reflecting upon or communicating about this reality in a comprehensive and/or objective fashion. As a result of these limitations, it could be the case that two perspectives are more-or-less sound but also fundamentally incompatible (Zizek 2009).

Recognition of this possibility informs many lines of traditional thought-from the popular parable of "The Blind Men and an Elephant" to mystical assertions that paradoxes hold the highest truths. In these instances, to eliminate contradictions (for instance, by privileging one perspective at the expense of all others, or by privileging common ground at the expense of points of divergence) is to achieve elegance by impoverishing understanding of the phenomenon in question. Accordingly, even if we stipulate the existence of objective moral truths, it may be erroneous to pursue some universal (conceptual, legal) frame for understanding, expressing or realizing these truths (Dancy 2007).
} 
Asad, Talal (2003), Formations of the Secular: Christianity, Islam, Modernity (Stanford: Stanford University Press).

Bar-Anan, Yoav, T.D. Wilson \& R.R. Hassin (2010), "Inaccurate self-knowledge formation as a result of automatic behavior", Journal of Experimental Social Psychology, 46: 884-94.

Bhabha, Homi (2004), The Location of Culture ( $2^{\text {nd }}$ ed.) (London: Routledge).

Bichierri, Cristina (2005), The Grammar of Society: The Nature and Dynamics of Social Norm. (Cambridge: Cambridge University Press).

Chambers, Robert (1999), Whose Reality Counts? Putting the First Last $\left(2^{\text {nd }}\right.$ ed.), (Bradford: Intermediate Technology Publications).

Clark, Andy \& Josefa Toribio (1994), "Doing without Representing?" Synthese, 101: 401-31.

Cosmides, Leda \& John Tooby (1992), "Cognitive Adaptations for Social Exchange", in J. Barkow, L. Cosmides, J. Tooby (eds.), The Adapted Mind: Evolutionary Psychology and the Generation of Culture (Oxford: Oxford University Press), 163-228. .

Dancy, Jonathan (2007), “An Unprincipled Morality”, in Russ Shafer-Landau (ed.), Ethical Theory: An Anthology (Hoboken: Wiley-Blackwell), 771-4.

Davidson, Donald (1982), "Paradoxes of Irrationality", in Richard Wollheim \& James Hopkins (eds.), Philosophical Essays on Freud (Cambridge: Cambridge University Press), 289-305.

Easterlin, Richard (2005), "Diminishing Marginal Utility of Income? Caveat Emptor", Social Indicators Research, 70(3): 243-55.

Easterly, William (2006), The White Man's Burden: Why the West's Efforts to Aid the Rest Have Done So Much Ill and So Little Good (London: Penguin Books).

Easterly, William (2014), The Tyranny of Experts: Economists, Dictators and the Forgotten Rights of the Poor (New York: Basic Books).

Fetzer, James H. (1990), "Evolution, Rationality, and Testability”, Synthese, 82 (3.2): 423- 439.

Feyerabend, Paul (2010), Against Method (4 ${ }^{\text {th }}$ ed.) (New York: Verso).

Foucault, Michel (2010), The Archaeology of Knowledge \& The Discourse on Language (New York: Vintage Books).

Foucault, Michel (1994), The Order of Things: An Archaeology to the Human Sciences (New York: Vintage Books).

Gallese, Vittorio \& George Lakoff (2005), "The Brain's Concepts: The Role of the Sensory-Motor System in Conceptual Knowledge", Cognitive Neuropsychology, 22: 455-79.

Gaus, Gerald F. (2009), "The Place of Autonomy Within Liberalism", in John Christman \& Joel Rogers (eds.), Autonomy and the Challenges to Liberalism: New Essays (Cambridge: Cambridge University Press), 272- 304.

Gendler, Tamar S. (2008), “Alief and Belief”, Journal of Philosophy, 105: 634- 663. al-Gharbi, Musa (2014), Building on Nietzsche's Prelude: Reforming Epistemology for the Philosophy of the Future (Boca Raton: Universal Publishers). 
Gigerenzer, Gerd \& Ulrich Hofferage (1995), "How to Improve Bayesian Reasoning Without Instruction: Frequency Formats”, Psychological Review, 102 (4): 684704.

Gillespie, Michael A. (2009), The Theological Origins of Modernity (Chicago: University of Chicago Press).

Gilbert, Daniel \& Timothy D. Wilson (2000), "Miswanting: Some problems in the forecasting of future affective states", in Joseph Forgas (ed.), Thinking and feeling: The role of affect in social cognition (Cambridge: Cambridge University Press), 178-99.

Graham, Carol \& Stefano Pettinato (2001), "Frustrated Achievers: Winners, Losers, and Subjective Well-Being in New Market Economies", Brookings Institution: Center on Social and Economic Dynamics Working Paper Series, 21.

Hadot, Pierre (1995), Philosophy as a Way of Life: Spiritual Exercises from Socrates to Foucault (Hoboken: Wiley-Blackwell).

Haidt, Jonathan (2012), The Righteous Mind: Why Good People Are Divided by Politics and Religion (New York: Vintage).

Haidt, Johnathan, Fredrick Bjorklund \& Scott Murphy (2000), "Moral Dumbfounding: When Intuition Finds No Reason", Lund Psychological Reports, 1(2): 1-29.

Halpern, Diane (2011), Sex Differences in Cognitive Abilities (4 ${ }^{\text {th }}$ ed.) (London: Psychology Press).

Henrich, Joseph (2015), The Secret of Our Success: How Culture is Driving Human Evolution, Domesticating Our Species, and Making Us Smarter (Princeton: Princeton University Press).

Hertwig, Ralph \& Peter M. Todd (2003), "More is Not Always Better: the Benefit of Cognitive Limits", in David Hardman \& Laura Macchi (eds.), Thinking: Psychological Perspectives on Reasoning, Judgment, and Decision-Making (Hoboken: Wiley \& Sons Ltd.), 213- 232.

Hurka, Thomas (1996), Perfectionism (Oxford: Oxford University Press).

Johnson, Marcia K. (1997), "Source Monitoring and Memory Distortion", Philosophical Transactions, B 352: 1733- 45.

Kahan, Dan M (2007), "The Cognitively Illiberal State”, Stanford Law Review, 60: 102-40.

Kahan, Dan (2010), "Fixing the Communications Failure", Nature, 463: 296-7.

Kahneman, Daniel \& Angus Deaton (2010), "High income improves evaluation of life but not emotional well-being", Proceedings of the National Academy of Sciences of the United States of America, 107 (38): 16,489- 16,493.

Kazmi, Zaheer (2014), The Limits of Muslim Liberalism. Los Angeles Review of Books: 4 April.

Kornblith, Hilary (1999), "Distrusting Reason", Midwest Studies in Philosophy, XXIII: $181-96$.

Kucera, Joshua (2013), "Voting Against Freedom", The Wilson Quarterly (Winter).

Kuhn, Thomas S. (1996), The Structure of Scientific Revolutions ( $3^{\text {rd }}$ ed.) (Chicago: University of Chicago Press). 
Lais, Hasnet (2013), "Are female converts to Islam part of a new wave of feminism?", The Independent: 8 February.

Lakoff, George \& Mark Johnson (1999), Philosophy in the Flesh: The Embodied Mind and its Challenge to Western Thought (New York: Basic Books).

Lakoff, George \& Rafael Nunez (2001), Where Mathematics Comes From: How the Embodied Mind Brings Mathematics into Being (New York: Basic Books).

Loftus, Elizabeth (1998), "Memory Distortion and False Memory Creation", Bulletin of the American Academy of Psychiatry and the Law, 24 (3): 281-95.

MacIntyre, Alasdair (1989), Whose Justice? Which Rationality? (Notre Dame: University of Notre Dame Press).

Markus, H.R. \& Barry Schwartz (2010), "Does Choice Mean Freedom and WellBeing?", Journal of Consumer Research, 37 (2): 344-55

Mercier, Hugo (2010), "The Social Origins of Folk Epistemology", Review of Philosophy and Psychology, 1 (4): 499-514.

Miller, Michael (2015), "Electoral Authoritarianism and Human Development", Comparative Political Studies, 48 (12): 1526-62.

Morozov, Evgeny (2013), To Save Everything, Click Here (New York: Public Affairs).

Nagel, Thomas (1991), Equality and Partiality (Oxford: Oxford University Press).

Nietzsche, Friedrich (2011), On the Genealogy of Morals (2 ${ }^{\text {nd }}$ ed.) (Cambridge: Cambridge University Press).

Nisbett, Richard E. (2003), The Geography of Thought: How Asians and Westerners Think Differently... and Why (New York: The Free Press).

Nisbett, Richard E. \& Timothy Wilson (1977), "Telling More Than We Can Know: Verbal Reports on Mental Processes", Psychological Review, 84 (3): 231 - 59.

Nozick, Robert (2013), Anarchy, State and Utopia (New York: Basic Books).

Nussbaum, Martha (2000), "Women \& Cultural Universals", in Sex and Social Justice (Oxford: Oxford University Press), 29-54.

- (2007), Frontiers of Justice: Disability, Nationality, Species Membership (Cambridge: Belknap Press).

- (2011), "Perfectionist Liberalism and Political Liberalism", Philosophy \& Public Affairs, 39 (1): 3-45.

- (2013), The New Religious Intolerance: Overcoming the Politics of Fear in an Anxious Age (Cambridge: Belknap Press).

Penny, Laurie (2011), Meat Market: Female Flesh Under Capitalism (Winchester: Zero Books).

Polanyi, Michael (1974), Personal Knowledge: Towards a Post-Critical Philosophy (Chicago: University of Chicago Press).

- (2009), The Tacit Dimension (Chicago: University of Chicago Press).

Popper, Karl (2013), The Open Society and Its Enemies (1-Volume Ed.) (Princeton : Princeton University Press).

Priest, Graham (2003), Beyond the Limits of Thought (Oxford: Oxford University Press). 
- (2008), An Introduction to Non-Classical Logic: From If to Is (Cambridge University Press).

Quine, W.V. (2008), “Two Dogmas of Empiricism”, in Roger F. Gibson Jr. (ed.), Quintessence: Basic Readings from the Philosophy of W.V. Quine (Cambridge: Belknap Press), 31- 53.

Rawls, John (2001), "A Kantian Conception of Equality”, in Samuel Freeman (ed.), Collected Papers (Cambridge: Harvard University Press), 254.

- (1971), A Theory of Justice (Cambridge: Harvard University Press).

- (2005), Political Liberalism ( $2^{\text {nd }}$ ed.) (New York: Columbia University Press).

- (2010), "The Law of Peoples", in The Law of Peoples with 'The Idea of Public Reason Revisisted (Cambridge: Harvard University Press), 11-128.

Raz, Joseph (1987), "Autonomy, Morality and the Harm Principle", in Ruth Galvin (ed.), Issues in Contemporary Legal Philosophy (Oxford: Oxford University Press), 313-33.

- (2000), Engaging Reason: On the Theory and Value of Action (Oxford: Oxford University Press).

Rushton, J.P. \& A.R. Jensen (2005), "Thirty Years of Research on Race Differences in Cognitive Ability”, Psychology, Public Policy \& Law, 11 (2): 235-94.

Sahlins, Marshall (1974), Stone Age Economics (Chicago: Aldine Transaction).

Schmitter, Phillipe C. (1994), "Dangers and Dilemmas of Democracy". Journal of Democracy, 5 (2): 57-74.

- (1995), "More Liberal, Preliberal or Postliberal?", Journal of Democracy, 6 (1): $15-22$.

Sen, Amartya (2005), "Human Rights and Capabilities", Journal of Human Development, 6 (2): 151-66

Shams, Alex (2012), “Misreading Feminism \& Women's Rights in Tehran: Beyond Chadors, Ninjabis \& Secular Feminists", Ajam Media Collective: 30 June.

Sterelny, Kim (2003), Thought in a Hostile World: The Evolution of Human Cognition (Hoboken: Blackwell Publishing Ltd.).

- (2012), The Evolved Apprentice: How Evolution Made Humans Unique (Cambridge: MIT Press).

Taleb, Nassim N. (2012), Antifragile: Things that Gain from Disorder (New York: Random House).

Taylor, Charles (2003), Modern Social Imaginaries (Durham: Duke University Press).

Todd, Peter M., Laurence Fiddick, \& Stefan Krauss (2010), "Ecological rationality and its contents", Thinking and Reasoning, 6 (4): 375-84.

Uhlmann, E.L., David Pizarro, David Tannenbaum, \& Peter Ditto (2009), "The Motivated Use of Moral Principles”, Judgment and Decision Making, 4 (6): 47691.

Van Gelder, Tim (1995), "What Might Cognition Be, If Not Computation?", The Journal of Philosophy, 92 (7): 345- 81.

Weinberg, Jonathan, Shaun Nichols \& Steven Stich (2001), "Normativity and Epistemic Intuitions", Philosophical Topics, 29 (1/2): 429-60. 
West, Richard F., Russell Meserve \& Keith Stanovich (2012), "Cognitive Sophistication Does Not Attenuate the Bias Blind Spot", Journal of Personality and Social Psychology, 103 (3): 506-19.

Wittgenstein, Ludwig (2009), Philosophical Investigations (4 ${ }^{\text {th }}$ ed.) (Hoboken: WileyBlackwell).

Youngs, Richard (2015), The Puzzle of Non-Western Democracy (Washington D.C.: Carnegie Endowment for International Peace).

Zakaria, Fareed (2007), The Future of Freedom: Illiberal Democracy at Home and Abroad (revised edition) (New York: W.W. Norton \& Company).

Zerubavel, Eviatar (1999), Social Mindscapes: An Invitation to Cognitive Sociology (Cambridge: Harvard University Press).

Zizek, Slavoj (2009), The Parallax View (Cambridge: MIT Press). 